\title{
De Nosso Território Sabemos Nós: experiência de cartografia social para emergências e desastres
}

\author{
Of Our Territory, We Know: social mapping experience \\ for emergencies and disasters
}

Simone Santos Oliveira (https://orcid.org/0000-0002-1477-749X) ${ }^{1}$
Sergio Portella (https://orcid.org/0000-0002-1514-7449) ${ }^{2}$
Cristiane Tiemi Yoshikawa (https://orcid.org/0000-0003-1598-4658) ${ }^{3}$
Dacy Lobosco (https://orcid.org/0000-0002-2022-4816) ${ }^{4}$
Leonardo Freire Dias (https://orcid.org/0000-0002-3743-1547) ${ }^{5}$
Thaís Candido de Oliveira (https://orcid.org/0000-0003-1369-9140) ${ }^{1}$

${ }^{1}$ Centro de Estudos de Saúde do Trabalhador e Ecologia Humana, Escola Nacional de Saúde Pública Sergio Arouca, Fundação Oswaldo Cruz. Rua Leopoldo Bulhões 1480 Prédio $1^{\circ}$ de Maio, Manguinhos. 21041-210 Rio de Janeiro RJ Brasil. simone@ensp.fiocruz.br ${ }^{2}$ Estratégia Fiocruz para a Agenda 2030, Presidência, Fundação Oswaldo Cruz. Rio de Janeiro RJ Brasil. ${ }^{3}$ Secretaria Municipal de Desenvolvimento Social de Teresópolis. Teresópolis RJ Brasil.

${ }^{4}$ Centro Federal de

Educação Tecnológica Celso Suckow da Fonseca. Nova

Friburgo RJ Brasil.

${ }^{5}$ Secretaria Municipal

de Meio Ambiente e

Desenvolvimento Urbano

Sustentável de Nova

Friburgo. Nova Friburgo

RJ Brasil.

\begin{abstract}
The article presents the project "OfOur Territory, We Know" (De Nosso Território Sabemos Nós), carried out in two communities in the mountain cities of the state of Rio de Janeiro that suffered the 2011 disaster, aiming at creating a device for online communication, associated with social cartography, seeking to establish a dialogue between the city management and citizens in a permanent and dynamic way. The device allows local needs to be visible for the creation of public policies. The implementation of the Extended Research Communities (Comunidades Ampliadas de Pesquisa), consisting of residents and their associations, participants of the municipal management, and researchers in a regime of ecology of knowledges, took place through cartographic workshops. The identification of the vulnerabilities and potentials of the communities, the emergence of memories and local knowledges allow the strengthening of community resilience. Therefore, the appraisal of the experience in the creation of social cartographies brings out the group's sel$f$-awareness. The mapping process demonstrated how unknown the territories are to the municipal management and even to their inhabitants.

Key words Community resilience, Social cartography, Disasters, Vulnerabilities
\end{abstract}

Resumo O artigo apresenta o projeto De Nosso Território Sabemos Nós, em duas comunidades das cidades serranas fluminenses que sofreram o desastre de 2011, com o objetivo da criação de dispositivo para comunicação on-line, associado à cartografia social, buscando pôr em diálogo gestão e cidadãos de maneira permanente e dinâmica. $O$ dispositivo permite que as necessidades locais sejam visíveis para deliberação de politicas públicas. A constituição das Comunidades Ampliadas de Pesquisa, composta por moradores e suas associações, participantes da gestão municipal e pesquisadores em regime de ecologia dos saberes, se realizaram através de oficinas cartográficas. A identificação das vulnerabilidades e potencialidades das comunidades, o aflorar das memórias e conhecimentos locais permitem o fortalecimento da resiliência comunitária. Dessa forma, a valorização da experiência na elaboração das cartografias sociais faz emergir a autoconsciência do grupo. $O$ processo de mapeamento demonstrou o quanto os territórios são desconhecidos para a gestão municipal e até mesmo para seus moradores.

Palavras-chave Resiliência comunitária, Cartografia social, Desastres, Vulnerabilidades 


\section{Introdução}

O ano de 2020 chega ao fim indicando um conjunto de desafios que não havíamos nos preparados para enfrentar, apesar dos inúmeros indicativos de estudos do Painel Intergovernamental de Mudanças Climáticas (IPCC) sobre o clima e dos Princípios de Bankok sobre saúde e desastres que alertavam para a inviabilidade do atual modelo de desenvolvimento e seus reflexos sobre os modos de vida, diante das mudanças climáticas ${ }^{1}$. Uma associação entre desigualdades, vulnerabilidades e aceleração das mudanças ambientais, expressas em desastres, nos colocaram diante de situações, onde a pandemia de COVID-19 é seu caso mais emblemático ${ }^{2}$, com resultados ainda não compreendidos e que exigirão de nós, determinação e vontade política para enfrentarmos seus desdobramentos. Algo que esses mesmos estudos destacavam: sem a organização cidadã dos territórios as soluções ficam distantes, abstratas e incomensuráveis.

A Estratégia de Redução de Riscos e Desastres, da Organização Nações Unidas (EIRD/ ONU) é uma instituição de referência pela sua produção compartilhada com a maioria dos países apontando o que é prioritário hoje nessa área. Isso já pode ser visto em seus primeiros documentos como Living with Risk: A global review of disaster reduction initiatives ${ }^{3}$, que avaliava os $\mathrm{dez}$ anos de vigência do Plano de Ação de Yokohama (1994) e preparava para o encontro que iria gerar o Marco de Hyogo 2005-2015, precursor do atual Marco de Sendai 2015-20304.

Nesse documento, central é o tema da construção da resiliência de comunidades, por entender que desastres são mais do que rupturas temporárias a serem gerenciadas apenas com resposta humanitária; e seus impactos não são reduzidos apenas por intervenções técnicas, pois estão intimamente relacionados a atividades de desenvolvimento sustentável nos campos social, econômico e ambiental. Dito de outra forma pelo mesmo documento, risco e vulnerabilidade são dois componentes das emergências e desastres. E para prevenir, responder e reconstruir, as ações de redução de desastres devem se basear em uma avaliação contínua da vulnerabilidade no território $^{3}$. Resiliência é, em geral, entendida como um produto interativo das crenças, atitudes e comportamentos vivenciados pelas pessoas, que podem ajudá-las a se sair melhores em situações de adversidade e se recuperarem mais rapidamente ${ }^{5}$.

Dessa forma, aumentar a resiliência implica em reduzir a vulnerabilidade de comunidades e sociedades, atuando nas dimensões física, social, econômica, ambiental e simbólica, com o objetivo de prevenir e atenuar os efeitos adversos dos perigos naturais, da degradação ambiental e dos perigos tecnológicos.

No entanto, não devemos deixar de destacar todos os debates em torno do conceito de resiliência, que tem sua origem nas medições da capacidade da liga do aço em retornar a suas condições sem se partir, e que ao generalizar soluções, pode menosprezar a plasticidade da adaptabilidade humana ao meio. Isso porque em uma situação adversa o mais importante é a sua própria singularidade expressa na combinação da compreensão das vulnerabilidades e do suporte disponível no território ${ }^{6}$. Nesse sentido da plasticidade, recorremos ao conceito de vida enquanto "atividade normativa" em Canguilhem ${ }^{7}$, ao afirmar que o ser humano é definido por sua capacidade de instituir novas normas de vida, a partir dos constrangimentos e possibilidades que lhe são impostos pelo meio. Isto é, o que pode parecer anormal pode indicar um novo modo de andar a vida. Em suas palavras: na medida em que seres vivos se afastam do tipo específico, serão eles anormais que estão colocando em perigo a forma específica, ou serão inventores a caminho de novas formas? $(\mathrm{p} .110)^{8}$

Em países como Brasil, não considerar a capacidade de normatividade do ser humano pode ser dramática e perigosa e desnaturalizar o que parece geral, e normal, pelos documentos multilaterais são fundamentais para a superação das emergências e desastres. Compreender como um determinado território foi ocupado e gerido por determinada população é condição para transformar os processos de vulnerabilização e apoiar soluções, muitas vezes, não vislumbradas. Importante linha de pensamento da sociologia dos desastres brasileira que preza a valorização dos estudos desses processos, respeitando a memória dos territórios e dos nexos sócio-históricos que o conformaram ${ }^{9}$. Não encarar o desastre como uma fatalidade natural, mas indicar a possibilidade de se escrever uma nova história com a envergadura dos conhecimentos comunitários e sua resiliência.

Pode-se ver a mesma indicação nos trabalhos $^{10}$ que definem a resiliência comunitária como a mobilização de recursos e capacidades solidárias da população para promover transformações físicas e sociais, também chamada "escudo protetor", que emerge das próprias condições de vida e valores da comunidade e permite uma metabolização do evento negativo e a possibilidade de construir a partir dele.

Através da avaliação da resiliência em diversas comunidades que sofreram desastres, Ojeda ${ }^{11}$ 
identificou os pilares da resiliência comunitária: solidariedade, honestidade estatal, identidade cultural, autoestima coletiva e humor social. Características muito especiais que necessitam da humildade epistemológica dos peritos para poderem ser consideradas ativamente nos esquemas de soluções sociotécnicas padronizadas.

Para isso, tanto especialistas como os mesmos documentos multilaterais mencionados anteriormente concordam que é preciso diminuir a distância entre gestão/peritos e cidadãos. No entanto, a maioria das soluções propostas acaba entregando o protagonismo dessa relação somente à gestão e aos peritos. Mais do que uma ação consciente, elas expressam um modo estruturado de nossa organização social capitalista. Como indica Michel Callon ${ }^{12}$, o modelo de ação da gestão ocidental está calcado no que chama de dupla delegação. Nela, o cidadão delega duplamente as decisões do seu dia-a-dia aos gestores e aos peritos, que acaba invisibilizando conhecimentos e soluções comunitárias situadas, fundamentais para o enfrentamento das vulnerabilidades que ali já estavam antes do desastre em função do modelo de desenvolvimento. Modelo generalizado para todas as áreas da sociedade, baseado na administração científica do trabalho das indústrias que isola o operário das decisões, no chãode-fábrica. A direção e os especialistas controlam a produção. Em determinado território, a dupla delegação dominante, principalmente em situações de emergências sanitárias e desastres, tende a não favorecer os movimentos de resiliência comunitária. E é por isso, que segundo Callon ${ }^{12}$ este modelo está em crise, desde a década de 1970. Integrar os coletivos comunitários é um caminho necessário, e combinar os conhecimentos da gestão, especialistas e cidadãos, simetricamente, para assim, transformar.

Neste artigo, tratamos da experiência do projeto De Nosso Território Sabemos Nós realizada em duas comunidades das cidades serranas fluminenses que sofreram o desastre de 2011, que buscou contribuir para a superação dessa dupla delegação. Ela se realiza pelo desenvolvimento de um sistema colaborativo, a partir de um dispositivo de comunicação on-line, baseado nas cartografias sociais. A construção de mapas interativos e participativos dos riscos e vulnerabilidades, necessidades e potencialidades de seus territórios, permite que os conhecimentos locais sejam visíveis na deliberação de políticas públicas. Essa experiência se ancora no princípio de reconstruir melhor, quarto eixo de ação do Marco de Sendai, com foco na prevenção.

\section{Sistemas colaborativos de cartografar}

Repetimos: parece uma obviedade, mas, pela organização de nossa sociedade não é uma tarefa fácil diminuir a distância entre gestão e cidadãos, pois a combinação da gestão com os peritos, em dupla delegação, desmobiliza os coletivos e sua possível resiliência. $\mathrm{O}$ desastre das cidades serranas é também exemplo disso. Em janeiro de 2011, essas cidades, vivenciaram um evento climático extremo considerado o maior desastre brasileiro da combinação de chuvas intensas, movimento de massa e transbordamento de rios, que culminou em mais de mil óbitos ${ }^{13}$. Perdas e danos na região, estimativas do Banco Mundial apontaram para custos totais da ordem de hum bilhão de dólares. Dentre estes custos, aproximadamente $60 \%$ atingiu o setor público ${ }^{14}$. Um desastre que dez anos depois se transformou para além da triste lembrança em uma herança que seus cidadãos devem dar conta, recheado de ineficiências organizacionais, despreparo de gestão e improbidade administrativas e corrupção. E que impactou e reorganizou todo o sistema nacional de proteção e defesa civil. Tal situação singular, mas também estrutural, diz mais sobre nosso modelo de desenvolvimento do que descreve o próprio evento adverso. Desastres e emergências sanitárias entendidos como processos de vulnerabilização devem mais aos seus nexos sócio-históricos do que a seus eventos detonadores. Constatação que também serve para a atual pandemia de COVID-19 e que aponta, mais uma vez, para a necessidade urgente da aproximação entre gestão, peritos e participação cidadã, para os enfrentamentos de seus desafios, que muitas vezes se transformam na desfiliação social de grupos inteiros com a sua exclusão $0^{15}$.

Dessa perspectiva, o conhecimento do território e das necessidades da comunidade são fundamentais no combate aos de riscos de desastres e emergências em saúde ${ }^{16}$. Os conhecimentos, normalmente, estão dispersos por vários sistemas, instituições, atores sociais e, localmente, na comunidade. Fortalecer os movimentos comunitários se configura, condição essencial para que novos regimes de produção de saber possam emergir para produzir novos modos de andar a vida $^{7}$, não ignorando a inércia que a dupla delegação provoca nas comunidades.

Para fortalecer é preciso conhecer, mapear riscos e vulnerabilidades a partir de quem vive as situações. Historicamente, na década de 1970, uma importante experiência foi realizada por Oddone e colaboradores ${ }^{17}$, conhecido como Modelo Operário Italiano (MOI), na luta pela saúde dos trabalhadores. 
Para Oddone ${ }^{18}$ estava claro que os trabalhadores desenvolvem um saber a partir da experiência de trabalho sem, muitas vezes, perceber, valorizar, potencializar ou conseguir transmitir esta experiência. Assim, procurou desenvolver métodos que pudessem auxiliar tanto na formalização, como na transmissão da chamada experiência operária. É neste sentido que introduz a ideia de uma comunidade científica ampliada a partir da noção dos limites de nocividade, o que colocava em questão a interpretação dos resultados das análises científicas, que seriam aceitas somente após validação consensual por parte do grupo homogêneo.

A elaboração de mapas de risco se torna a base para a construção de uma pauta de reivindicações concreta e sistematicamente sustentada. O objetivo metodológico fundamental desta proposta é introduzir a percepção subjetiva do trabalhador como critério de avaliação da nocividade, sem delegar estes critérios exclusivamente a especialistas. Torna protagonista o grupo que vive submetido à mesma nocividade e que acumulou um saber epidemiológico leigo no que diz respeito às relações entre $o$ ambiente $e$ os sofrimentos $e$ adoecimentos que o acometem; que toma consciência do alcance cultural de sua experiência e se reconhece como grupo homogêneo.

A experiência das cartografias sociais vai na mesma direção. Segundo Harley ${ }^{19}$, a cartografia oficial sempre foi uma forma de conhecimento e de poder. O cartógrafo, conscientemente ou não, não reproduz somente o território em sentido abstrato, mas também os imperativos territoriais de um sistema político. Pela seletividade de seu conteúdo e por seus símbolos e estilos de representação, os mapas são um meio de imaginar, articular e estruturar o mundo. Aceitando-se tais premissas, torna-se mais fácil compreender a que ponto eles se prestam às manipulações por parte dos que detêm o poder na sociedade. As bases cartográficas e os mapas geralmente são produzidos por técnicos especializados, sob o interesse de instituições públicas e privadas em dupla delegação com a gestão.

Possibilitar que as próprias comunidades produzam suas cartografias é uma ação contra hegemônica. Diversas iniciativas de mapeamento que se propõem a incluir populações locais nos processos de produção de mapas disseminaramse, em todo o mundo. O conceito de cartografia social surge, no início da década de 1990, com o projeto Nova Cartografia Social da Amazônia. Com o apoio de sindicatos, associações, movimentos, cooperativas, grupos têm utilizado o mapa social como forma de afirmar direitos em diferentes contextos e veem na cartografia uma maneira de expor seus processos de territorialização e sua identidade ${ }^{20}$.

Em função do lugar, a cartografia serve para muitos fins de organização comunitária. Em alguns, ela contribuirá na incidência política direta e irá fortalecer identidades coletivas; e outros, irá tornar visíveis ao público fenômenos vividos por certos grupos e coletivos sociais. A cartografia, assim, aglutina pessoas e as leva a estruturar narrativas da vida comunitária que se desenrola nos territórios, auxiliando a enxergar relações desse imenso tecido associativo dos quais fazemos parte e hoje se transforma ${ }^{21}$.

Assim, o mapa social só existe a partir da participação efetiva e incondicional da população envolvida $^{22}$. Essa característica do mapa social potencializa uma outra característica do mapa, muitas vezes esquecida, de que ele não é algo fechado, mas um processo permanente de construção. Garantir a expressão dessa potencialidade tem, hoje, mais um aliado que são os sistemas colaborativos on-line.

Segundo Souza e colaboradores ${ }^{23}$, o sucesso dos Sistemas Colaborativos envolve mudanças no comportamento e na cultura, ao induzir as pessoas a compartilhar e colaborar tornando-as ativas no processo de gerar, receber e transmitir conhecimento. Num contexto de comunidade de prática, viabilizada por artefatos tecnológicos permite conectar pessoas, fortalece e cria um senso de grupo, fazendo com que apareça um aprendizado coletivo, explícito, público, relevante, ordenado e claro.

Dado o potencial das tecnologias disponíveis, a interação entre cidadãos e instituições, governamentais e/ou não governamentais, se potencializa e possibilita a criação de serviços de maior relevância e representatividade para o cidadão ${ }^{24}$.

Nessa perspectiva, é que buscamos a criação de dispositivo de comunicação on-line, associado a cartografia social, para pôr em diálogo gestão/ academia/cidadãos de maneira permanente e dinâmica.

\section{Percurso metodológico}

A trajetória metodológica aqui apresentada é resultado de um longo caminhar do grupo de pesquisa com e nos territórios atingidos pelo desastre de 2011. Tem como referências a produção do documentário 11.11.2011 Experiência-Limite, disponível na internet, e a realização do I Seminário Internacional de Desnaturalização dos Desastres-2015 ${ }^{25}$. Essa vivência abriu espaço para 
maior aproximação desses territórios, no ano de 2019, com a construção das cartografias sociais em duas comunidades, mais afetadas - Caleme, em Teresópolis e Córrego D’Antas, em Nova Friburgo. O desastre desorganizou esses territórios, com perdas materiais e simbólicas, que têm suas marcas até hoje, nas paredes das casas, nas falhas das montanhas, nas ruinas das construções interditadas, nos vazios deixados pelas famílias deslocadas ou perdidas. Evidências dispersas no território e presentes nas memórias dos moradores que necessitam ser consideradas e respeitadas, para o fortalecimento dessas comunidades.

Para tanto, seguimos a experiência exitosa do $\mathrm{MOI}^{17}$ com toda discussão revisitada por Yves Schwartz $^{26}$ através do Dispositivo Dinâmico a Três Polos (DD3P) ou Comunidade Ampliada de Pesquisa (CAP), assim denominada por pesquisadores brasileiros ${ }^{27}$.

O DD3P é um dispositivo de trabalho cooperativo e de formação que coloca em diálogo três diferentes polos: dos saberes organizados ou das disciplinas (gestores, peritos e acadêmicos); das forças de convocação e validação (que diz respeito aos saberes investidos na atividade cidadã propriamente dita); regulados pelo terceiro polo das exigências éticas/epistêmicas (que busca a simetria dialógica entre esses saberes tanto os territoriais locais quando os dos conhecimentos disciplinares) ${ }^{26}$.

Acrescentamos à nossa caixa de ferramentas a ideia da ecologia dos saberes desenvolvida por Boaventura Santos ${ }^{28}$, um processo coletivo de produção de conhecimentos que visa reforçar as lutas pela emancipação social. Uma estratégia para enfrentar as condições de incerteza de nossa época, para não desperdiçar experiências sociais disponíveis e nem classificar como impossíveis experiências sociais emergentes ${ }^{29}$.

O lançamento do projeto e explicação de seus objetivos foi realizado um primeiro encontro em Córrego D’Antas, essa apresentação se deu durante uma reunião regular do grupo gestor da associação de moradores. No Caleme, o projeto foi apresentado durante a posse da nova diretoria eleita da associação e contou com a presença de mais de 40 pessoas. As comunidades apoiaram a execução do projeto e as Associações de Moradores abrigaram a proposta viabilizando espaço para que ocorressem os encontros.

A construção das CAP em cada território se deu de maneira diferente, com a realização de quatro oficinas para desenvolvimento das cartografias sociais. Sempre aos sábados, uma vez por mês (de agosto a novembro de 2019). A associação de Córrego D’Antas tem sede própria, enquanto o Caleme se utiliza do espaço anexo da principal igreja católica do bairro para realização de seus encontros. Com antecipação, os encontros eram divulgados na comunidade, através de cartazes e contatos diretos com lideranças para multiplicação da informação. Participaram em média vinte pessoas entre moradores, profissionais ligados as Secretarias Municipais da saúde, defesa civil, desenvolvimento social e ambiente, além do grupo de pesquisadores. As oficinas eram iniciadas com uma dinâmica em roda e, no final do encontro, se voltava à roda para um fechamento (Quadro 1).

Com a duração média de quatro horas, a maior parte do tempo da oficina era utilizado para a discussão das vulnerabilidades e potencialidades da comunidade, a partir dos mapas produzidos e modificados anteriormente. Os mapas para a primeira oficina foram produzidos pela equipe. Os posteriores já eram resultados dos trabalhos compartilhados.

Os participantes assinaram o Termos de Consentimento Livre e Esclarecido (TCLE) aprovados pelo Comitê de Ética de Pesquisa da Escola Nacional de Saúde Pública Sergio Arouca (ENSP/ Fiocruz).

\section{Resultados e discussão}

A comunidade do Caleme está localizada no corredor ecológico que conecta o Parque Nacional da Serra dos Órgãos e Parque Natural Municipal Montanhas de Teresópolis, ocupando 0,874 km². Neste fluxo de dispersão e movimento para manutenção da biodiversidade, habitam cerca de cinco mil moradores. Suas casas estão distribuídas entre as encostas e as margens do Rio Imbuí. A paisagem vem se transformando desde o desastre ocorrido em janeiro de 2011, no entanto, ainda se pode ver resquícios dos escombros e de casas interditadas, que estão sendo utilizadas como destinação final de resíduos, promovendo a infestação de ratos e queima de materiais.

A comunidade do Córrego D’Antas, possui aproximadamente $19 \mathrm{~km}^{2}$ e está localizado na unidade territorial de planejamento, bacia do rio Bengalas. Estima-se a ordem de cinco mil habitantes que estão distribuídos às margens da RJ-130 que liga Nova Friburgo a Teresópolis, às margens do Córrego D’Antas e das encostas de Zonas de Especial Interesse Ambiental (ZEIA), Zona Urbana Controlada (ZUC) e Zonas de Expansão Orientada (ZEO).

A construção das cartografias sociais realizada nas oficinas junto aos moradores dos bairros 


\begin{tabular}{|c|c|c|c|c|c|}
\hline \multirow[t]{6}{*}{  } & Quadro 1. D & nâmicas das Oficina & Cartográficas. & & \\
\hline & \multirow{2}{*}{ Dinâmicas } & \multicolumn{4}{|c|}{ Oficinas cartográficas } \\
\hline & & Primeira - Agosto & Segunda - Setembro & Terceira - Outubro & Quarta - Novembro \\
\hline & Nome & Árvore dos desejos & Mural das intenções & Teia comunitária & Sentimento que trago \\
\hline & Materiais & $\begin{array}{l}\text { Galho de árvore } \\
\text { seco } \\
\text { Fitas coloridas } \\
\text { Pilot }\end{array}$ & $\begin{array}{l}\text { Papel pardo } \\
\text { Recortes de revistas } \\
\text { com imagens e } \\
\text { palavras } \\
\text { Tesoura, Cola, Pilot }\end{array}$ & Rolo de barbante & \\
\hline & Descrição & $\begin{array}{l}\text { Os participantes } \\
\text { sentados em roda } \\
\text { são convocados a } \\
\text { escrever um desejo } \\
\text { (ou mais) nas } \\
\text { fitas. Em seguida, } \\
\text { cada participante } \\
\text { enuncia seu desejo, } \\
\text { se levanta e amarra } \\
\text { sua fita no galho } \\
\text { disposto no centro } \\
\text { da roda }\end{array}$ & $\begin{array}{l}\text { Elaboração de mural } \\
\text { para representação } \\
\text { da comunidade } \\
\text { através da escolha } \\
\text { de palavras, frases e } \\
\text { imagens disponíveis } \\
\text { no centro da roda } \\
\text { ou que criadas/ } \\
\text { desenhadas na hora }\end{array}$ & $\begin{array}{l}\text { Para a construção da teia, os } \\
\text { participantes em roda e de pé } \\
\text { escolhiam um membro para } \\
\text { jogar o rolo de barbante e assim } \\
\text { sucessivamente. O anterior segurava } \\
\text { um pedaço deste, para que, ao final a } \\
\text { teia estivesse formada } \\
\text { Antes de jogar o rolo cada integrante } \\
\text { falava um elemento da natureza ou da } \\
\text { sociedade para ser guardião: animais, } \\
\text { água, natureza, sol, cachoeira, pessoas, } \\
\text { rua, árvores, famílias etc } \\
\text { Ao final a teia é desfeita cada } \\
\text { participante devolvendo o } \\
\text { rolo e repetindo o guardião do } \\
\text { companheiro/a }\end{array}$ & $\begin{array}{l}\text { Sentados em roda, } \\
\text { cada um é solicitado } \\
\text { que cada participante } \\
\text { declare e explique } \\
\text { o sentimento que } \\
\text { trouxe para o } \\
\text { encontro }\end{array}$ \\
\hline
\end{tabular}

Fonte: Elaborado pelos autores.

Caleme e Córrego D’Antas fez emergir a memória das/os atingidas/os sobre a tragédia de 2011. As marcas na identidade coletiva resultantes das vidas perdidas, das casas destruídas, e das iniciativas estatais de requalificação territorial, demolindo residências e reconstruindo habitações em outras localidades, esfacelando o sentimento de pertencimento ao lugar ${ }^{30}$. Situação que em muitos casos significou sua desterritorialização $0^{31}$. Contudo, lembranças de muita resistência e reconstrução. Dessa forma, o projeto teve excelente aceitação e engajamento dos diferentes grupos, estabelecendo-se uma agenda para as oficinas cartográficas.

\section{Primeira oficina cartográfica}

Na primeira oficina para a elaboração da cartografia comunitária (Córrego D’Antas-10/08, Caleme-31/08), a dinâmica de apresentação foi conduzida pela árvore dos desejos. Em um galho de árvore seco, aos poucos, os participantes da roda escreveram em fitas um desejo para si e para a comunidade, na perspectiva do bem comum.

A comunidade do Caleme demarcou suas questões fundamentais: mobilidade urbana; descarte de lixo; áreas do rio mais poluídas; ruas com esgoto a céu aberto; demarcação de pontos de apoio e localização das sirenes; e demarcação de áreas de proteção ambiental. Nessa comunidade os moradores apresentaram as necessidades do bairro: farmácia, horta comunitária, mais supermercados, calçamento de ruas e cobertura dos pontos do ônibus e iluminação pública.

Em Córrego D'Antas, as demarcações se voltaram para as instituições de educação; de saúde; as fábricas no bairro; depósitos irregulares de lixo e aterro sanitário da cidade saturado - localizado no bairro, ocorrendo o despejo de chorume no rio; os moradores salientaram a inexistência de coleta de lixo na parte mais alta do bairro, que resulta na queima do lixo; também destacaram a falta de áreas de lazer e cultura.

No contato com os mapas elaborados pela equipe e parceiros dos projetos a partir dos dados levantados, puderam validar as informações e acrescentar o que consideravam relevantes. Localizaram nos mapas os problemas discutidos anteriormente. No entanto, pediram mapas em que pudessem reconhecer melhor território. A seguir trechos de falas partilhadas no grupo.

Empatia e valor comum, eu acho que as vezes a barreira de dificuldade da empatia é exatamente porque a gente entende que nosso valor é maior 
e mais forte que o valor do outro. A gente ignora que existe valor que não é o meu e nem do outro, mas que é um valor comum. (Morador Córrego D’Antas)

Depois de todo mundo colocar as fitinhas com as palavras eu fiquei pensando, tem uma palavra que dá força a todas essas outras que colocamos ali, a realização, que essas palavras e sentimentos se realizem. (Moradora do Caleme)

\section{Segunda oficina cartográfica}

A segunda oficina cartográfica (Córrego D’Antas-21/09, Caleme-28/09) teve início com a elaboração de um mural construído coletivamente, em que cada participante pôde escolher uma imagem, frase e/ou palavra, para pensar no bem comum da comunidade. Esse mural coletivo abriu caminho para se contemplar as necessidades da comunidade em seus respectivos mapas, através da localização e debates sobre suas questões.

Na comunidade de Córrego D’Antas, os moradores destacaram: a redução do tamanho do rio que corta o bairro =; esgotos que caem direto no rio; locais que necessitam de obras de contenção e pavimentação; despejo de agrotóxico no rio - sendo possível ver a coloração da água do rio mudar. E propuseram a construção da estação de tratamento de esgoto, a efetivação do projeto de um parque em torno do rio, e solicitaram de novo mapa de risco para o bairro por parte da defesa civil.

No Caleme, as ações sobre os mapas foram de correção e validação de legendas, e demarcação: de áreas com lixo e falta de esgotamento, de locais poluídos que contaminam as nascentes do bairro, de áreas de risco de deslizamento e locais que necessitam de obras de contenção, e de pontos de apoio em caso de emergência. As principais propostas de melhorias para o bairro foram: necessidade de um posto de saúde e a construção de áreas de lazer, especialmente para as crianças.

Os mapas foram completamente reconstruídos nas duas comunidades. $\mathrm{E}$ a equipe considerou a possibilidade de realizar um registro a partir de fotografias de drone.

Escolhi história por quê nesse momento estamos fazendo parte da história do Caleme e precisamos também resgatar a nossa história, eu peguei essa figura pois me lembro do Vale dos Eucaliptos, precisamos preservar para que daqui um tempo as pessoas possam fazer parte dessa história. (Moradora Caleme)

Eu vou escrever uma palavra que representa bastante o momento que a gente tá vivendo que é uma filosofia africana, ubuntu, que significa: eu sou o que sou graças ao que nós somos; que significa que a comunidade só cresce a partir do momento que ela entende que juntos somos mais fortes. (Morador Córrego D'Antas)

\section{Terceira oficina cartográfica}

A dinâmica da teia da vida abriu a terceira oficina cartográfica nas comunidades (Caleme-19/10, Córrego D’Antas-26/10). Cada participante se apresentou e escolheu uma representação/elemento para ser o guardião. Com a teia de barbante formada entre eles, trouxeram sentimentos vivenciados com as chuvas de 2011. Percebeu-se o quão estão conectados, a importância do cuidado e de como somos positivamente dependentes uns dos outros.

No Caleme, os participantes se debruçaram nos mapas para validar os dados anteriores e acrescentarem legendas com foco em locais com possíveis desmoronamentos e descarte de lixos; demarcação de áreas de difícil acesso; de ruas sem asfalto e sem iluminação; proposta de novas rotas de fuga em caso de emergências; sugestões de novos pontos de apoio e de locais para a instalação de um posto de saúde. Foram apontadas construções irregulares em área de reserva ambiental; e optou-se em marcar o rio em vermelho com traços pretos indicando os locais com maior vulnerabilidade quando há chuvas.

Em Córrego D’Antas aconteceu a correção e validação de legendas. Discussão sobre a localização da creche na autoestrada e a necessidade de sinalização adequada; falta de quadra de esportes adequada para uso; demarcação de ruas com problemas de pavimentação; as Igrejas Evangélicas e o Centro Espírita; pontos de descarte de lixo; com o alerta para o perigo de um depósito de carros. Foi feita a proposta de se chamar lideranças das localidades - Sapolândia e Dois Esquilos - que estavam sem representação para agregarem informações ao mapa.

Assim estamos conectados e um cuidando do outro. Para estar aqui hoje um depende do outro, então pensar em trabalhar com mapa, trabalhar um com o outro, com amigo, o vizinho, sabendo desse equilíbrio, do respeito e amor por tudo que nos rodeia, essa é a mensagem dessa teia. (Moradora Caleme)

O território é formado pelas pessoas e coisas, então tem tudo tem a ver com a lua, as relações e o bairro. Com relação a isso tudo o próprio Córrego Dantas é um bom exemplo de resistência e relação que após desastre foi muito boa, com relação a se organizar, estruturar e agir politicamente. (Moradora Córrego Dantas) 
Nas duas comunidades, para superar a falta de conformidade do Google Maps, a equipe do projeto apresentou mapas realizados pelas imagens do drone proporcionando uma visão fidedigna do território. Esses mapas possibilitaram as comunidades se reconhecerem melhor e facilitaram a consolidarem das informações levantadas desde o primeiro encontro.

\section{Quarta oficina cartográfica}

Nesta última oficina (Caleme-16/11, Córrego D’Antas-30/11) foi realizada uma apresentação com um filmete-síntese de todas as discussões e fotos dos encontros. O filmete inicia com a imagem do planeta e vai fechando até focar na imagem da comunidade. O mapa final de cada comunidade foi fixado na parede para que todos pudessem ver. Na dinâmica, em roda, cada participante pode dizer o sentimento que o animava, após vivenciar as lembranças dos outros encontros.

No Caleme, houve apresentação do mapa comunitário consolidado e novamente surgiu a necessidade de instalação de posto de saúde. Aproveitou-se da presença do secretário municipal de saúde na reunião, que se comprometeu em viabilizar a necessidade. $O$ representante da secretaria de defesa civil apresentou a proposta de construção de censo das comunidades da cidade e se propôs a dialogar sobre as ações que o projeto desenvolverá; também houve grande discussão sobre o uso sustentável do lixo, oficinas de reciclagem. Apresentou os desdobramentos do projeto como o censo comunitário vivo e a construção memória do bairro.

No Córrego D’Antas, durante a apresentação do mapa comunitário consolidado, realizouse discussões sobre a questão do lixo e formas de utilização reciclável; canais de comunicação como igrejas para mobilização de jovens e pessoas a participarem do projeto e das ações como o censo e registro da memória do bairro.

Quando a gente chegou e algumas pessoas olharam o mapa, eu mesma quase chorei, pois não era uma imagem do nada, ver as fotos... Gostaria de deixar claro que essas informações foram colocadas no primeiro momento e a cada vez que a gente se encontra, a gente tem mais coisas a dizer e a cada momento que a gente vive ela vai se complementando e agora teremos o aplicativo. (Técnica - Secretaria de Desenvolvimento Social, Caleme).

Eu acho que [o aplicativo] seria importante porque no bairro tem buraco, às vezes precisa de asfalto, eu acho que todos esses problemas como a questão deles lá em cima do ônibus. Portanto, acho que é importante, pois através do aplicativo pode fotografar imediatamente e já saber que tem problema naquele local. (Moradora Caleme)

Nessas últimas oficinas de cartografia, teceuse novos elos na rede de encontros e valorização de experiências e saberes com outros atores locais, como o grupo do Parque do Parnaso. A cartografia contribui para emergir a autoconsciência do grupo como indicam Gorayeb e Meireles ${ }^{22}$, a construção e o desenvolvimento de identidades próprias.

Na sequência e para finalizar esses encontros foi apresentado o planejamento do aplicativo e discutiram-se possibilidades do seu funcionamento às ações subsequentes (Figuras 1 e 2).

\section{$O$ aplicativo garantindo os dinamismos das CAPs}

O aplicativo desenvolvido, e já em teste, possibilita que uma pessoa da comunidade forneça um relato da sua necessidade, crítica, ou sugestão podendo enviar uma fotografia inclusive, e após aprovação do conteúdo pela associação de moradores, esse relato passa a estar visível e disponível para outras pessoas da comunidade interagirem com o relato, podendo aprovar (like) ou desapro-

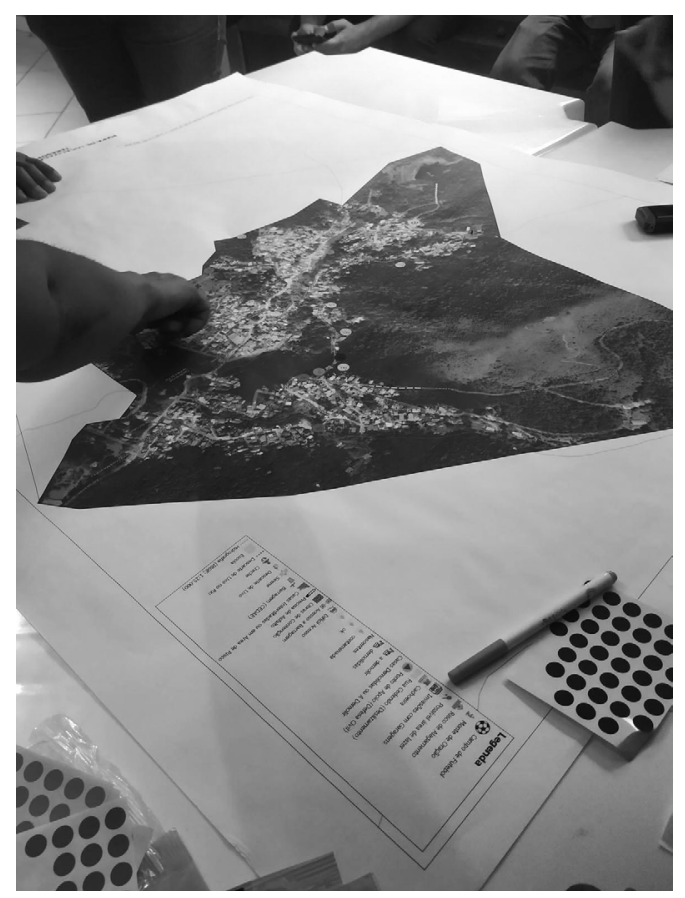

Figura 1. Mapa Caleme.

Fonte: Dos autores. 


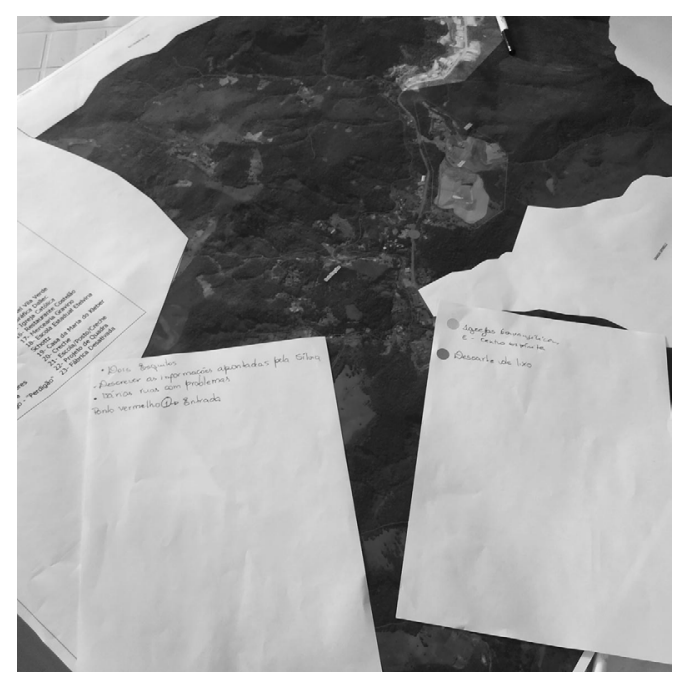

Figura 2. Mapa Córrego D’Antas.

Fonte: Dos autores.

var (unlike), ou podendo colocar comentários. A solução proposta por consequência produz um nível de memória das discussões gerando um conhecimento acumulado em um processo democrático (Figura 3), o que favorece a deliberação da associação de moradores em tornar um relato, uma demanda coletiva, que por sua vez é informada e destinada ao representante do poder público municipal para o seu conhecimento como uma demanda da comunidade.

Com relação aos processos podemos detalhar as diversas interfaces dos moradores para enviarem relatos, os detalhes podem ser observados na Figura 4.

Nesta perspectiva, a solução visa fortalecer a democracia deliberativa, mas também, substantiva, pois com base nos dados das necessidades relatadas pela população facilita a transparência para a decisão política e deliberativa por parte das associações de moradores a que pertencem. A associação de moradores por sua vez irá aglutinar e respaldar as demandas da população, que via a ferramenta, provocará o poder público municipal responsável por responder tais demandas.

É fundamental, nesta fase, para consolidação das CAPs e implementação do aplicativo a construção de uma linguagem comum. Um co- nhecimento novo que promova um desenvolvimento mútuo e formativo desses protagonistas do território, dos técnicos e gestores municipais e dos próprios pesquisadores, a partir do reconhecimento do outro e de seus saberes como legítimos, conforme aponta Boaventura Santos, numa ecologia dos saberes ${ }^{29}$.

A experiência de construção das CAPs tem potencial agregador de outros dispositivos que buscam romper com a herança de vulnerabilidade e apostam na tessitura de um novo saber aderente, territorial, comunitário. Assim, esses movimentos reafirmam o conceito de vida enquanto atividade normativa em Canguilhem ${ }^{8}$, ao dizer que o ser humano é definido por sua capacidade de instituir novas normas de vida, a partir dos constrangimentos e possibilidades que lhe são impostos pelo meio.

\section{Considerações finais}

Ao valorizar as experiências e vivências, através das oficinas cartográficas, na perspectiva de transformar os modos de andar a vida vislumbramos junto com os protagonistas e parceiros do projeto a possibilidade de sua ampliação para outras comunidades, constituindo uma rede. $\mathrm{O}$ desafio de sua escalabilidade depende de maior entrosamento com a gestão municipal e engajamento de outras localidades. A parceria com instituições de pesquisa e ensino são promissoras.

Identificar vulnerabilidades é um modo de praticar resiliência comunitária. Lembramos, em homenagem às cidades que receberam os fóruns mundiais de Redução de Risco e Desastres, todas no Japão, uma técnica nipônica de restauro de cerâmicas danificadas e rachadas. O kintsugi é uma técnica para restaurar cerâmicas, com a mistura de laca e ouro em pó, muitas vezes deixando o objeto restaurado mais valioso e mais resistente do que antes. As oficinas das cartografias sociais demonstraram o quanto os territórios são desconhecidos para a gestão municipal e até para seus moradores. No horizonte de permanente incerteza em que vivemos, a afirmação de que o meio é sempre infiel parece-nos uma verdade incômoda que não podemos evitar. Temos que transformar esse conhecimento em vantagem. Parece que é justamente o que precisamos, restaurar melhor com base nos territórios para enfrentar o mundo que se avizinha.

Esperamos que a experiência aqui compartilhada siga nessa direção. 


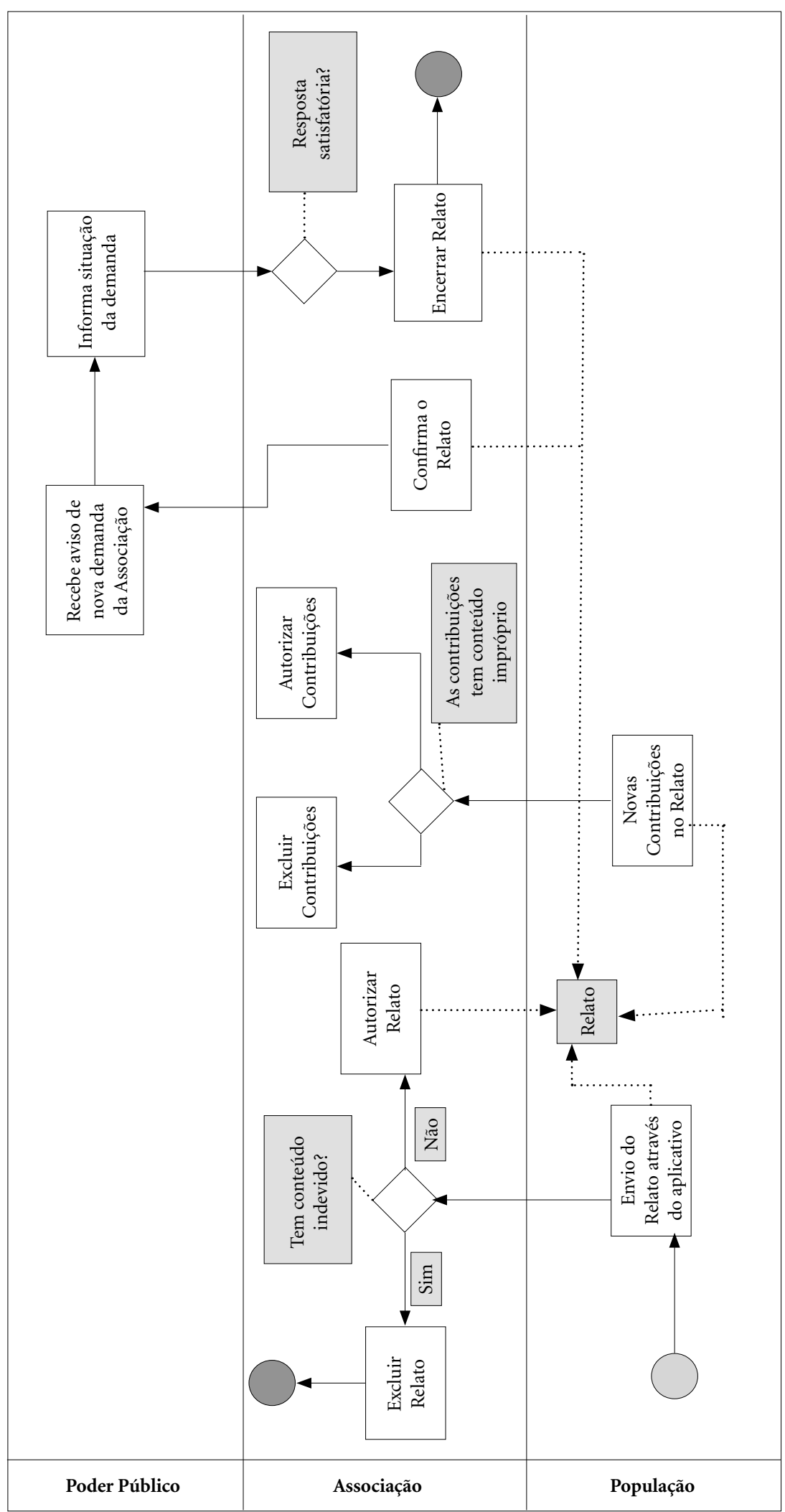

Figura 3. Processo de construção democrática.

Fonte: Elaborado pelos autores. 

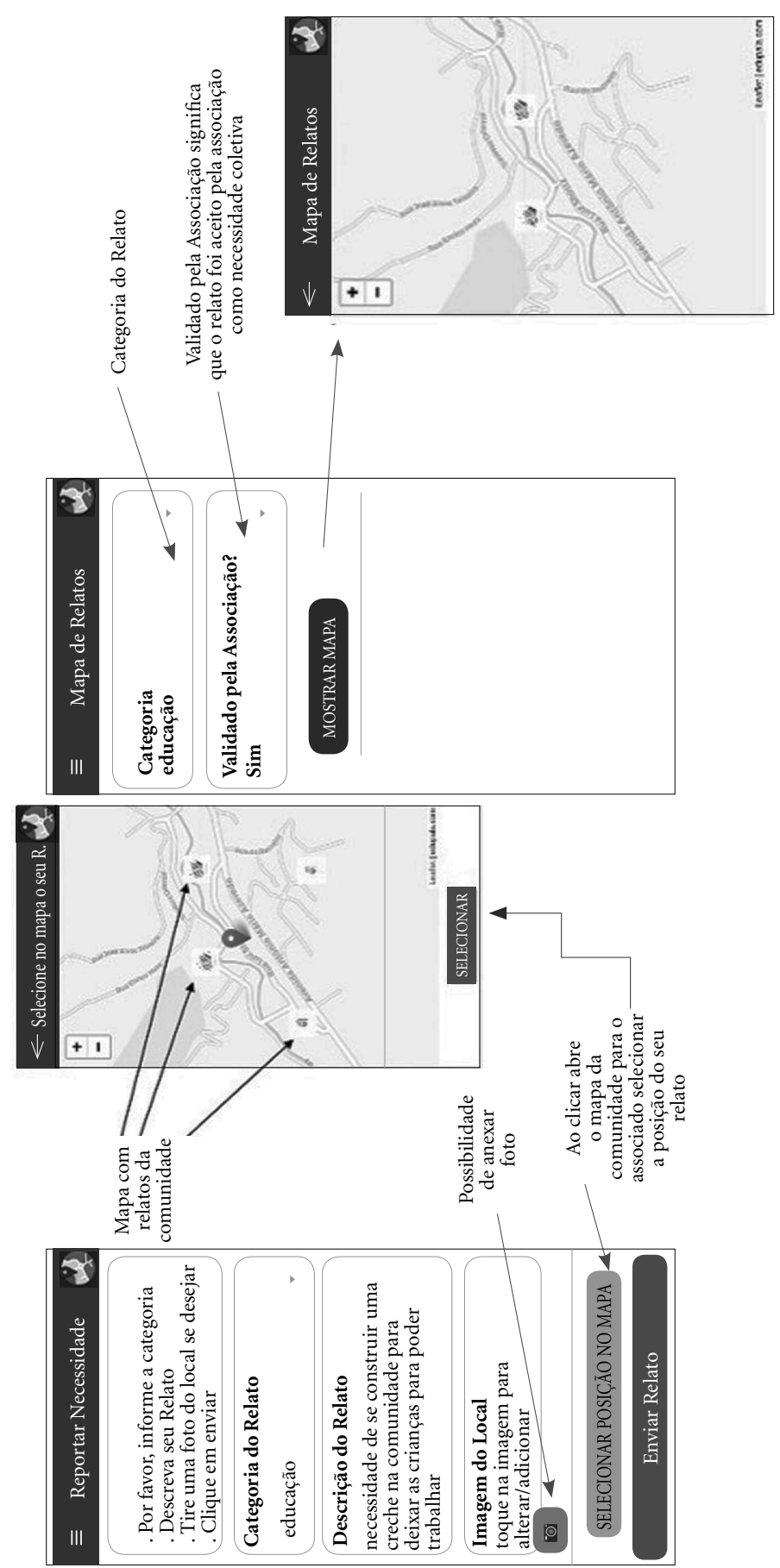

Figura 4. Modelo de envio de relato.

Fonte: Elaborado pelos autores.

\section{Colaboradores}

SS Oliveira, S Portella, CT Yoshikawa, DC Lobosco, LF Dias e TC Oliveira contribuíram de maneira efetiva na concepção, planejamento e redação do manuscrito. SS Oliveira e S Portella realizaram a revisão e aprovação da versão final do manuscrito. 


\section{Referências}

1. Bankoff G. Time is of the essence: disasters, vulnerability and history. Int J Mass Emerg Disasters 2004; 22(3):23-42.

2. Portella S, Oliveira S.S. A naturalização da pandemia no Brasil. Observatório do Risco-OSÍRIS, 14/06/2020. CES/Universidade de Coimbra; 2020.

3. United Nations Office for Disaster Risk Reduction $\mathrm{Li}$ ving with Risk: A global review of disaster reduction initiatives. UNDRR; 2004. 429 p. [acessado 2020 nov 08]. Disponível em: https://www.undrr.org/publication/living-risk-global-review-disaster-reduction-initiatives

4. United Nations Office for Disaster Risk Reduction (UNISDR). Sendai Framework for Disaster Risk Reduction 2015-2030. Japão; 2015. [acessado 2020 nov 08]. Disponível em: http://www.preventionweb.net/ files/43291_sendaiframeworkfordrren.pdf.

5. Clark H. Building resilience the importance of prioritizing disaster risk-reduction. United Nations Development Programme Perspective, 2012. [cited 2019 fev 08]. Available from: http://www.undp.org/content/ undp/en/home/presscenter/speeches/2012/08/15/hel en-clark-building-resilience-the-importance-of-prioritising-disaster-risk-reduction-.html.

6. Mendes JM, Tavares, AO, Cunha L, Freiria S. A vulnerabilidade social aos perigos naturais e tecnológicos em Portugal. Rev Crit Cienci Sociais 2011; 93:95-128.

7. Canguilhem G. Meio e normas do homem no trabalho. Pro-posições 2001; 12(2-3):109-121.

8. Canguillhem G. O normal e o patológico. Rio de Janeiro: Forense Universitária; 2006. p. 110.

9. Valencio N. F. Elementos constitutivos de um desastre catastrófico: os problemas científicos por detrás dos contextos críticos. Cienc Cult 2016; 68(3):41-45.

10. Ojeda E. Uma concepção latino-americana: a resiliência comunitária. In: Melillo A, Ojeda E, Ojeda E, editores. Resiliência: Descobrindo as próprias fortalezas. Porto Alegre: Artmed; 2005.

11. Ojeda E, La Jara A, Márquez C. Resiliência Comunitária. In: L. Hoch L, Rocca S, editores. Sofrimento, resiliência e fé: implicações para as relações de cuidado. São Leopoldo: Sinodal; 2007.

12. Callon M, Lascoumes P, Barthe Y. Agir dans un monde incertain. Essai sur la démocratie technique. Paris: Seuil; 2001.

13. Portella SLD, Nunes JA. Populações serranas excluídas, cidades insustentáveis: o enigma da participação pública. Cien Saude Colet 2014; 19(10):4223-4228.

14. Freitas CM, Carvalho, ML, Ximenes EF, Arraes, EF, Gomes JO. Vulnerabilidade socioambiental, redução de riscos de desastres e construção da resiliência: lições do terremoto no Haiti e das chuvas fortes na Região Serrana, Brasil. Cien Saude Colet 2012; 17(6):1577-1586.

15. Valencio A, Valencio N. Subsídios à uma discussão comunitária acerca de modelagem da epidemia: relações dialógicas no enfrentamento de uma crise social e sanitária. In: Valencio N, Oliveira CM. Covid-19: crises entremeadas no contexto de pandemia (antecedentes, cenários e recomendações). São Carlos: UFSCar/CPOI; 2020.

16. Marchezini V, Yu Iwama A, Andrade MRM, Trajber R, Rocha, I, Olivato D. Geotecnologias para prevenção de riscos de desastres: usos e potencialidades dos mapeamentos participativos. Rev Brasil Cartografia 2017; 69(1):107-128.
17. Oddone I, Marri G, Gloria S, Briante G, Chiatella M, Re A. Ambiente de trabalho: a luta dos trabalhadores pela saúde. 2a ed. São Paulo: Hucitec; 2020.

18. Muniz HP, Brito J, Souza KR, Athayde M, Lacomblez M. Ivar Oddone e sua contribuição para o campo da Saúde do Trabalhador no Brasil. Rev Bras Saude Ocup 2013; 8(128):280-291.

19. Harley B. Mapas, saber e poder. Trad. Mônica Balestrin Nunes. Confins - Revista Franco-Brasileira de Geografia 2009; 5.

20. Acserlrad H, organizador. Cartografia social, terra e território. Rio de Janeiro: IPPUR/UFRJ; 2013.

21. Oliveira A, Guterres A, Barros J, Barros R. Cartografia Social Urbana: impactos do desenvolvimento e da violência institucional na vida das mulheres moradoras do Caju e de Manguinhos/ Rio de Janeiro. Rio de Janeiro: FASE; 2017.

22. Gorayeb A, Meireles J. Cartografia social vem se consolidando com instrumento de defesa de direitos. Rede Mobilizadores; 10 fev. 2014. [acessado 2017 nov 12]. Disponível em: http://www.mobilizadores.org.br/ coep/Publico/consultarConteudoGrupo.aspx?TP=V\&CODIGO=C20142610482831.

23. Souza JM, Sampaio JO, Costa VCF, Esteves MGP. Gestão do conhecimento e memória de grupo. In: Pimentel M, Fucks H, organizadores. Sistemas Colaborativos. Rio de Janeiro: SBC/Elsevier; 2011. p. 206-220.

24. Araujo RM, Cappelli C, Diirr B, Engiel P. Tavares, R. L. Democracia eletrônica. In: Pimentel M, Fucks H, organizadores. Sistemas Colaborativos. Rio de Janeiro: SBC/Elsevier; 2011.

25. Oliveira SS, Portella S, Siqueira A, Freitas M. Desnaturalização dos desastres e mobilização comunitária: Redes e Rodas. Cienc Trop 2016; 40 (1):13-36.

26. Schwartz Y. A comunidade científica ampliada e o regime de produção de saberes. Trab Educ 2000; 7:38-46.

27. Brito J, Atahyde M. Trabalho, educação e saúde: o ponto de vista enigmático da atividade. Trab Educ Saude 2003; 1(2):239-265.

28. Santos BS. A filosofia à venda, a douta ignorância e a aposta de Pascal. Rev Crit Cienc Sociais 2008, 80:11-43.

29. Santos BS. Para além do pensamento abissal: das linhas globais a uma ecologia de saberes, Novos Estud CEBRAP 2007; 79.

30. Tuan YF. Espaço e lugar: a perspectiva da experiência. São Paulo: Difel; 1983.

31. Guedes AD. Lutas por terra e território, desterritorialização e território como forma social. Revista Brasileira de Estudos Urbanos e Regionais 2016; 18(1):23-39.

Artigo apresentado em 20/11/2020

Aprovado em 24/05/2021

Versão final apresentada em 26/05/2021

Editores-chefes: Romeu Gomes, Antônio Augusto Moura da Silva 